Research Article

\title{
Development of UV Spectrophotometric Procedures for Determination of Amlodipine and Celecoxib in Formulation: Use of Scaling Factor to Improve the Sensitivity
}

\author{
Mahesh Attimarad (D), ${ }^{1}$ Katharigatta Narayanaswamy Venugopala ${ }^{(D)},{ }^{1,2}$ \\ Bandar E. Aldhubiab $\mathbb{D}^{1},{ }^{1}$ Anroop Balachandran Nair, ${ }^{1}$ Nagaraja SreeHarsha $\left(\mathbb{D},{ }^{1}\right.$ \\ Shinu Pottathil, ${ }^{3}$ and Sabah H. Akrawi $\mathbb{D D}^{1}$ \\ ${ }^{1}$ Department of Pharmaceutical Sciences, College of Clinical Pharmacy, King Faisal University, Al-Hofuf, \\ Al-Ahsa 31982, Saudi Arabia \\ ${ }^{2}$ Department of Biotechnology and Food Technology, Durban University of Technology, Durban 4001, South Africa \\ ${ }^{3}$ Department of Biomedical Sciences, College of Clinical Pharmacy, King Faisal University, Al-Hofuf, \\ Al-Ahsa 31982, Saudi Arabia
}

Correspondence should be addressed to Mahesh Attimarad; mattimarad@kfu.edu.sa

Received 30 June 2019; Revised 18 September 2019; Accepted 1 October 2019; Published 7 December 2019

Academic Editor: Sarfaraz Ahmed Mahesar

Copyright (c) 2019 Mahesh Attimarad et al. This is an open access article distributed under the Creative Commons Attribution License, which permits unrestricted use, distribution, and reproduction in any medium, provided the original work is properly cited.

\begin{abstract}
FDA has recently approved a new fixed-dose combination of amlodipine besylate (AMD) and celecoxib (COX) for the treatment of hypertension and osteoarthritis. No analytical method has been reported for analysis of these two analytes so far. Hence, to monitor the quality and quantity in the formulation of AMD and COX a simple, accurate, precise, economical, and eco-friendly spectroscopic analytical method has been established. The first method involves the determination of AMD and COX by the first derivative UV spectroscopic method with scaling factor 10. However, the second method was based on the direct measurement of UV absorbance of AMD at $364.3 \mathrm{~nm}$ and ratio first derivative UV spectroscopic method for COX. Both methods showed good linearity in the range of 5 to $40 \mu \mathrm{g} / \mathrm{ml}$ for COX, whereas AMD showed linearity in the range of 0.5 to $10 \mu \mathrm{g} / \mathrm{ml}$ in first derivative method with scaling factor 10 and 1 to $10 \mu \mathrm{g} / \mathrm{ml}$ in the second method with good correlation coefficient $\left(R^{2}>0.998\right)$. Both the methods were validated for LOD, LOQ, accuracy, precision, recovery studies, and stability as per the ICH guidelines, and the validated results were well within the acceptable range. Both the methods were successfully utilized for the determination of AMD and COX in the presence of each other in the formulation, and statistically compared between the proposed methods. Therefore, the proposed procedures can be utilized for regular quality control studies.
\end{abstract}

\section{Introduction}

Hypertension and osteoarthritis (OA) are major health problems in the middle- and old-age population. Generally, these two diseases coexist, and $40 \%$ of OA patients were diagnosed for hypertension [1]. However, the treatment for these two diseases is challenging, because of the adverse effects of NSAIDs on the blood pressure [2]. Nevertheless, celecoxib (COX, Figure 1(a)) was found to be a better choice because it has low risk on blood pressure than ibuprofen, naproxen, or other NSAIDs, and COX has low gastrointestinal and kidney toxicity $[3,4]$. Hence, FDA has recently approved a fixed-dose combination of calcium channel blocker, amlodipine besylate, and selective COX-2 inhibitor, celecoxib, for the treatment of hypertension and OA [5].

Amlodipine besylate (AMD, Figure 1(b)), a long-acting calcium channel blocker, is a dihydropyridine derivative extensively used for the management of hypertension and angina pectoris [6]. Several analytical methods were described in the literature for quantification of AMD alone and 


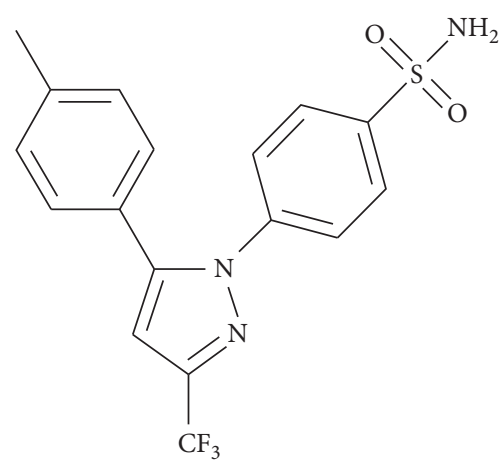

(a)

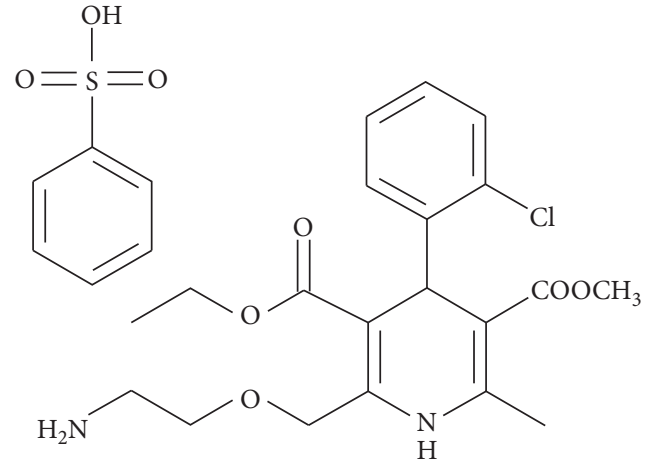

(b)

Figure 1: Chemical structure of celecoxib (a) and amlodipine besylate (b).

in combination with other drugs from formulation and biological fluids. These analytical methods include spectrophotometric methods [7-9], spectrofluorometric methods [10], HPTLC [11], RP-HPLC [12-14], LCMS/MS [15], capillary electrophoresis, and electrochemical methods [16-23]. Celecoxib, (COX) selective cox-2 inhibitor, is a potent analgesic, antipyretic, and anti-inflammatory drug. COX is far better than other traditional NSAIDs in terms of gastrointestinal safety profile, by sustaining the physiological amount of prostaglandins in the stomach and kidney. Hence, it is generally preferred in chronic inflammatory diseases such as OA $[24,25]$ and also been used in chemodefensive activity in different cancers [26]. The medicinal application of COX has been increasing continuously; hence, different analytical methods have also been reported, such as spectrophotometry $[27,28]$, spectrofluorometry $[28,29]$, RPHPLC [30-32], LCMS/MS, [33, 34], and capillary electrophoresis methods [35]. However, no analytical technique has been reported for simultaneous assessment of AMD and COX in recently approved pharmaceutical formulation.

UV spectroscopic methods are simple, economical, and accurate. However, for multicomponent formulations consisting of analytes showing a complete overlap of UV absorption spectra, it becomes difficult to estimate the analytes in the presence of each another using zero-order UV spectra without prior separation. However, derivatization of zeroorder spectra will allow us to analyze these components in the presence of each other, by measuring the peak amplitude of derivative spectra at zero crossings for one of the analyte. Furthermore, derivatization of ratio spectra can also be used to avoid the interference by another component and tablet excipients [36-40]. Hence, an attempt has been made in this proposal to develop two economical, simple, accurate, and precise derivative UV spectrophotometric methods for simultaneous determination of AMD and COX in pharmaceutical formulations.

\section{Experimental}

2.1. Chemicals and Reagents. Pure samples of amlodipine besylate $(99.1 \%)$ and celecoxib $(98.9 \%)$ were procured from the Sigma Aldrich (Germany). Analytical-grade ethanol was purchased from Sigma Aldrich. The distilled water prepared in our laboratory by Milli Q (Millipore, USA) was used throughout the experiments. Amlodipine tablet $(10 \mathrm{mg} /$ tablet) and celecoxib capsule $(200 \mathrm{mg} /$ capsule) were purchased from the local market. Tablets consisting of AMD: COX in a concentration of $2.5: 200,5: 200$, and $10: 200 \mathrm{mg} /$ tablet, respectively, were prepared in laboratory using $8 \mathrm{mg}$ of lactose, $5 \mathrm{mg}$ of magnesium stearate, $10 \mathrm{mg}$ microcrystalline cellulose, $12.5 \mathrm{mg}$ talc, and $10 \mathrm{mg}$ sodium starch glycolate per tablet.

2.2. Instruments. Shimadzu UV-Vis spectrophotometer (1700) has been used to record the UV spectra of AMD and COX using $10 \mathrm{~mm}$ quartz cuvettes. Scanning of the samples was performed at a speed of $50 \mathrm{~nm} / \mathrm{min}$ by adjusting the slit width to $1 \mathrm{~nm}$. At high concentration levels of analytes, spectra showed high noise; hence, spectra were smoothened with $8 \mathrm{~nm}$. Calibrated volumetric flasks were used for preparations of stock and working standards and sample solutions.

2.3. Preparation of Stock and Working Solutions. Stock solutions of AMD and COX standards were prepared by transferring precisely balanced $100 \mathrm{mg}$ of AMD and COX to two separate $100 \mathrm{ml}$ measuring flasks consisting of $50 \mathrm{ml}$ of ethanol. AMD was freely soluble in ethanol, whereas to dissolve COX, the measuring flask was mixed thoroughly for 5 min with the help of sonicator, and then the final volume was adjusted to the $100 \mathrm{ml}$ with ethanol. The working standards were prepared by diluting these solutions with ethanol: water $(50 \% \mathrm{~V} / \mathrm{V})$ as a solvent.

2.4. Preparation of AMD and COX Sample Solutions Using Formulation and Laboratory-Prepared Tablets. Twenty tablets of AMD (10 mg/tablet) were weighed, powdered, and the average weight was calculated. Twenty capsules of COX ( $200 \mathrm{mg} /$ Capsule) were opened and contents were weighed separately, the average weight was calculated, and then mixed. Both AMD and COX powder equivalent to $10 \mathrm{mg}$ of AMD and $200 \mathrm{mg}$ of COX were transferred to $100 \mathrm{ml}$ 
measuring flask. Around $75 \mathrm{ml}$ of ethanol was transferred and sonicated for $15 \mathrm{~min}$ at room temperature to dissolve the analytes into the solvent. The solution was filtered and the filter paper was washed with fresh ethanol and the final volume was adjusted with ethanol. Furthermore, the solution was diluted with $50 \%$ ethanol to bring the concentration in the range of calibration curve. Similarly, laboratoryprepared tablets were powdered and sample solutions were prepared using the above-mentioned procedure and analyzed.

\section{Procedure}

3.1. First Derivative Spectrophotometric Method (First Method). Sufficient amount of AMD and COX standard stock solutions were transferred into two separate series of $10 \mathrm{ml}$ volumetric flasks, to get concentration in the range of $0.5-10 \mu \mathrm{g} / \mathrm{ml}$ of $\operatorname{AMD}(0.5,2,4,6,8$, and $10 \mu \mathrm{g} / \mathrm{ml})$, and 5 to $40 \mu \mathrm{g} / \mathrm{ml}$ of $\operatorname{COX}(5,10,15,20,30$ and $40 \mu \mathrm{g} / \mathrm{ml})$. All these solutions were subjected to the absorption measurement in the range of $200 \mathrm{~nm}$ to $400 \mathrm{~nm}$ to record the UV absorption spectra using $50 \% \mathrm{v} / \mathrm{v}$ ethanol/water solution as blank. The first derivative spectra were computed for all these spectra using $4 \mathrm{~nm}$ as $\Delta \lambda$ with scaling factor 10 . The peak amplitude of AMD spectra at zero crossings for COX and peak amplitude for COX spectra at zero crossings for AMD were recorded. The calibration curves were constructed between these amplitude values against the corresponding concentration of AMD and COX separately and respective regression equations were constructed.

\subsection{Ratio First Derivative Spectroscopy (Second Method).} Sufficient amount of AMD stock solutions was transferred to a sequence of $10 \mathrm{ml}$ measuring flasks containing $20 \mu \mathrm{g} / \mathrm{ml}$ of COX to get the concentration in the level of 1 to $10 \mu \mathrm{g} / \mathrm{ml}$ $\operatorname{AMD}(1,2,4,6,8,10 \mu \mathrm{g} / \mathrm{ml})$. Similarly, COX standard stock solution was added to a sequence of $10 \mathrm{ml}$ measuring flasks consisting of $2 \mu \mathrm{g} / \mathrm{ml}$ of AMD to get the concentration in the range of 5 to $40 \mu \mathrm{g} / \mathrm{ml}$ of $\operatorname{COX}(5,10,15,20,30,40 \mu \mathrm{g} / \mathrm{ml})$. UV absorbance spectra were recorded for combined AMD and COX solutions and stored. The absorbance of AMD was measured at $363.4 \mathrm{~nm}$ and a calibration curve was constructed for AMD by plotting a graph between absorbance versus concentration. Separately, $2 \mu \mathrm{g} / \mathrm{ml}$ solution of AMD was prepared and the UV spectrum was recorded. The second series of absorbance spectra of AMD and COX were converted to ratio spectra of COX by dividing the combined spectra with UV spectrum of AMD $(2 \mu \mathrm{g} / \mathrm{ml})$. Resulting ratio spectra were converted into the first derivative of ratio spectra of COX by derivatizing with $4 \mathrm{~nm}$ as $\Delta \lambda$. The peak amplitude at $286.7 \mathrm{~nm}$ was measured, and the graph was constructed by plotting a graph between amplitude value and corresponding concentration. Regression equations were also calculated from calibration curves.

3.3. Application of UV Spectroscopic Methods to the Formulation. Aliquot of sample solution was diluted with $50 \%$ ethanol solution to get the working sample solution containing both AMD and COX $1: 20 \mu \mathrm{g} / \mathrm{ml}, 1: 40 \mu \mathrm{g} / \mathrm{ml}$, $0.5: 40 \mu \mathrm{g} / \mathrm{ml}$, respectively. UV absorption spectra were recorded in the range of $200 \mathrm{~nm}-400 \mathrm{~nm}$. For the first method, the normal UV spectra of sample solutions were converted into the first derivative using $4 \mathrm{~nm}$ as $\Delta \lambda$ with a scaling factor of 10 . The concentrations of AMD and COX were determined by recording the peak amplitude at zerocrossing wavelength and corresponding regression equations. In the second method, for determination of AMD, absorbance was measured at $364.3 \mathrm{~nm}$ and concentration was calculated using regression equitation. For determination of the concentration of COX, the normal UV spectrum of the formulation was divided by UV spectrum of AMD $(2 \mu \mathrm{g} / \mathrm{ml})$ and the resulted ratio spectrum was converted into a first derivative spectrum using $4 \mathrm{~nm}$ as $\Delta \lambda$. The peak amplitude was measured at $286.7 \mathrm{~nm}$, and the concentration of COX was calculated using the corresponding regression equation. Furthermore, both the methods were compared using Student's " $t$ " test and " $F$ " test to know the difference between the analysis results of both methods.

\section{Results and Discussion}

The UV absorption spectra for AMD and COX in ethanol/ water $(50 \% \mathrm{v} / \mathrm{v})$ solution are shown in Figure 2. The UV spectra of COX were completely overlapped by UV spectra of AMD, making it difficult to determine COX in presence of AMD without prior separation by direct UV spectrophotometry. Hence, two derivative UV spectrophotometric methods were developed for simultaneous determination of AMD and COX in formulations. The derivatization of UV spectra could allow us to determine the analytes in the presence of excipients and also remove the interference from the overlapping analyte.

Both the analytes were soluble in ethanol and in the concentration of calibration curve range, working standard solutions were clear solution in the $50 \%$ ethanol solution. Hence, $50 \%$ ethanol solution was selected as a solvent to develop simple, economical, and eco-friendly UV-spectroscopic methods.

The first method was based on the conversion of normal spectra into the first derivative spectra by differentiating the absorbance spectra of a sample by wavelength by wavelength. Derivative spectra allow us to separate overlapped spectra and also eliminate the interference by excipients and other analytes. This increases the resolution of multicomponent spectra and enhances specificity and sensitivity. Furthermore, this feature allows for the determination of the concentration of one component in the presence of others by measuring the amplitude of derivative spectra at zerocrossing wavelengths, where one of the components will have zero absorbance $[36,37]$.

The fixed-dose formulations of AMD and COX are available in three different ratios: $2.5: 200,5: 200$, and 10 : $200 \mathrm{mg} /$ tablet, respectively. Due to low concentration of AMD in the formulation compared to COX, at zero-crossing wavelength for COX, AMD showed negligible absorbance up to $2 \mu \mathrm{g} / \mathrm{ml}$ due to low amplitude of first derivative spectra. Hence, it was difficult to determine simultaneously both 


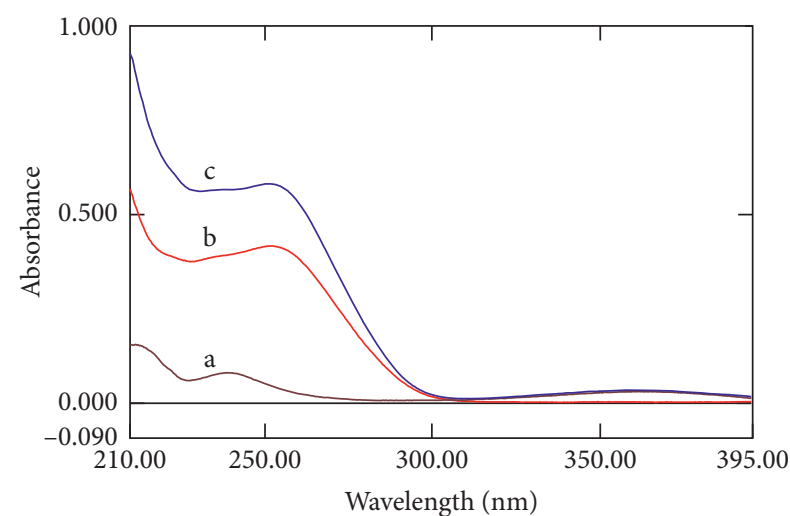

FIgURE 2: Normal UV absorption spectra of AMD (a), COX (b), and mixture (c).

analytes in a formulation containing 2.5:200 $\mathrm{mg}$ and 5: $200 \mathrm{mg}$ of AMD and COX. Therefore, with an increase in the concentration, AMD proportionally increases the concentration of COX. Absorption of COX solution, with a concentration above $40 \mu \mathrm{g} / \mathrm{ml}$, was more than 2.5 and showed noise. Hence, scaling factor of 10 was used during the conversation of spectra to first derivative spectra, which increases the amplitude of the first derivative spectra and allowed to determine the low concentration of AMD from $0.5 \mu \mathrm{g} / \mathrm{ml}$ (Figure 3).

Absorbance spectra were recorded for AMD and COX solutions and converted into first derivative spectra with a scaling factor 10 using $4 \mathrm{~nm}$ as $\Delta \lambda$. Different wavelengths 2 , 4,8 , and $10 \mathrm{~nm}$ were applied as $\Delta \lambda$. However, $4 \mathrm{~nm}$ was found to be optimal with scaling factor 10 ; hence, $4 \mathrm{~nm}$ was used as $\Delta \lambda$ throughout the experiment. The first derivative spectra of AMD showed 2 maxima at $233.16 \mathrm{~nm}$ and $338.34 \mathrm{~nm}$ and 3 minima at $-219.68 \mathrm{~nm},-249.22 \mathrm{~nm}$, and $-393.55 \mathrm{~nm}$ (Figure 4); however, COX showed zero crossings at $-252.0 \mathrm{~nm}$ at which AMD had some absorption amplitude (Figure 5). The first derivative spectra of COX showed 1 maximum at $245.59 \mathrm{~nm}$ and 2 minima at -209.8 and $-272.08 \mathrm{~nm}$ (Figure 6). However, AMD showed zero crossings at $-210.56 \mathrm{~nm}$ and $-289.4 \mathrm{~nm}$ where COX had some absorbance (Figure 5). However, the amplitude was good at $-210.5 \mathrm{~nm}$ but linearity was not good, whereas at $-289.4 \mathrm{~nm}$, amplitude is low but showed good linearity with excellent regression coefficient. Hence, wavelengths of $-252.0 \mathrm{~nm}$ and $-289.4 \mathrm{~nm}$ were selected for quantification of AMD and COX, respectively. Furthermore, analytes showed the same absorbance in pure and in presence of each other at zero-crossing wavelength (Figure 5).

The second method involves the direct measurement of AMD and ratio derivative method for COX measurement. Since UV spectra of COX showed no absorbance in the range of $320 \mathrm{~nm}$ to $400 \mathrm{~nm}$, where AMD had some absorbance, a calibration curve was constructed for AMD by measuring the absorbance at $363.4 \mathrm{~nm}$ (Figure 7). However, the spectra of COX was completely overlapped by AMD. Hence, ratio derivative spectroscopic method [38-40] has been adopted for quantification of COX, which is based on the following principle. For two compounds (P and Q) with

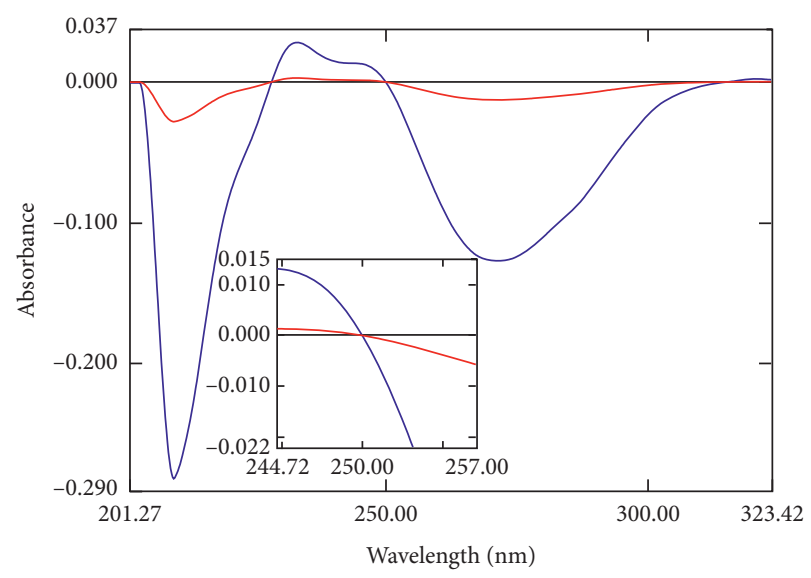

FIgURE 3: First derivative spectra of AMD $(0.5 \mu \mathrm{g} / \mathrm{ml})$ and COX $(10 \mu \mathrm{g} / \mathrm{ml})$ with scaling factor 1 (red) and scaling factor 10 (blue). Enlarged part shows the absorbance difference at $252 \mathrm{~nm}$.

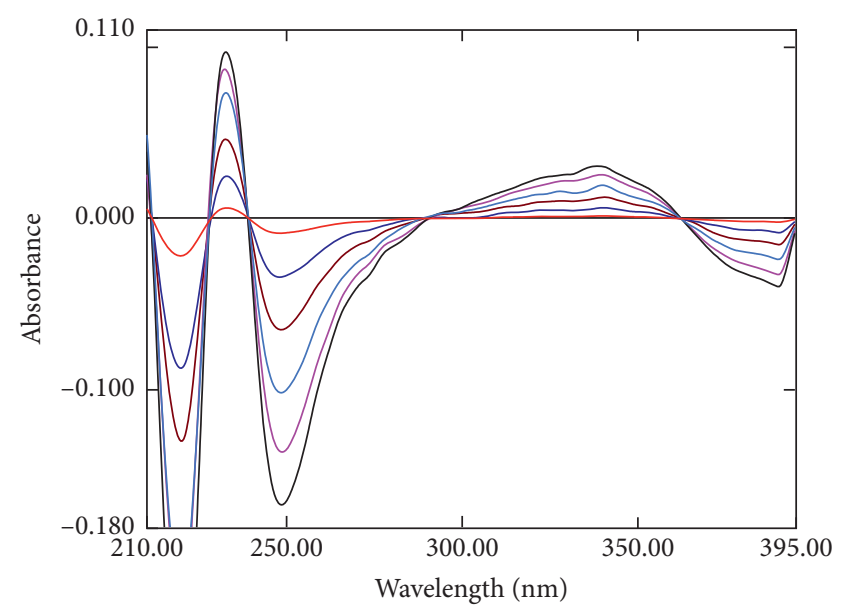

FIgure 4: The first-order derivative spectra of AMD 0.5 to $10 \mu \mathrm{g} / \mathrm{ml}$.

no chemical interaction between the compounds and which obey Beers' law for each compound, the following equation (1) can be constructed:

$$
A_{\mathrm{M}}=\varepsilon_{\mathrm{P}} C_{\mathrm{P}}+\varepsilon_{\mathrm{Q}} C_{\mathrm{Q}},
$$

where $A_{\mathrm{M}}$ is the absorbance of $\mathrm{P}$ and $\mathrm{Q}$ mixture, $\varepsilon_{\mathrm{P}}$ and $\varepsilon_{\mathrm{Q}}$ are molar absorptivity of compounds $\mathrm{P}$ and $\mathrm{Q}$, respectively, and $C_{\mathrm{P}}$ and $C_{\mathrm{Q}}$ are the concentration of compounds $\mathrm{P}$ and $\mathrm{Q}$, respectively. Dividing the above equation with absorbance equation of one of the pure compound solution spectra $\left(A_{\mathrm{Q}^{\circ}}=\varepsilon_{\mathrm{Q}^{\circ}} C_{\mathrm{Q}^{\circ}}\right)$ results into the following equation (2):

$$
\frac{A_{\mathrm{M}}}{A_{\mathrm{Q}^{\circ}}}=\frac{A_{\mathrm{P}}}{A_{\mathrm{Q}^{\circ}}}+\frac{C_{\mathrm{Q}}}{C_{\mathrm{Q}^{\circ}}} \text {. }
$$

The expression $C_{\mathrm{Q}} / C_{\mathrm{Q}^{\circ}}$ is constant, which can be eliminated by converting the ratio spectra to derivative spectra. This derivatization generates several maxima and minima, and measurement of peak amplitude at these maxima and minima wavelengths allows us to determine the concentration of one component in the presence of 


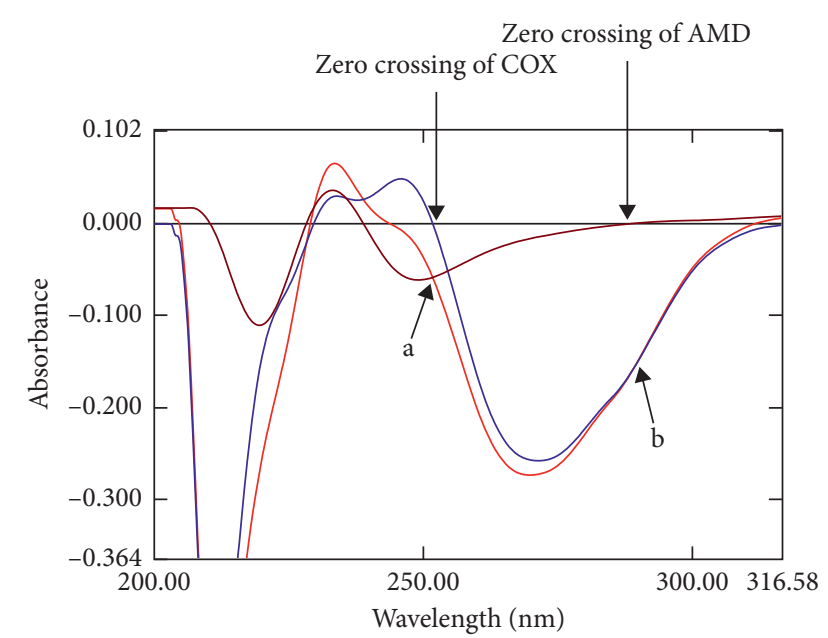

FIgURE 5: The first-order derivative spectra of AMD (brown), COX (blue), and a mixture of AMD and COX (red). (a) AMD $(4 \mu \mathrm{g} / \mathrm{ml})$ showing the same absorbance in pure and mixture at zero crossings for COX. (b) COX $(20 \mu \mathrm{g} / \mathrm{ml})$ showing the same absorbance in pure and mixture at zero crossings of AMD.

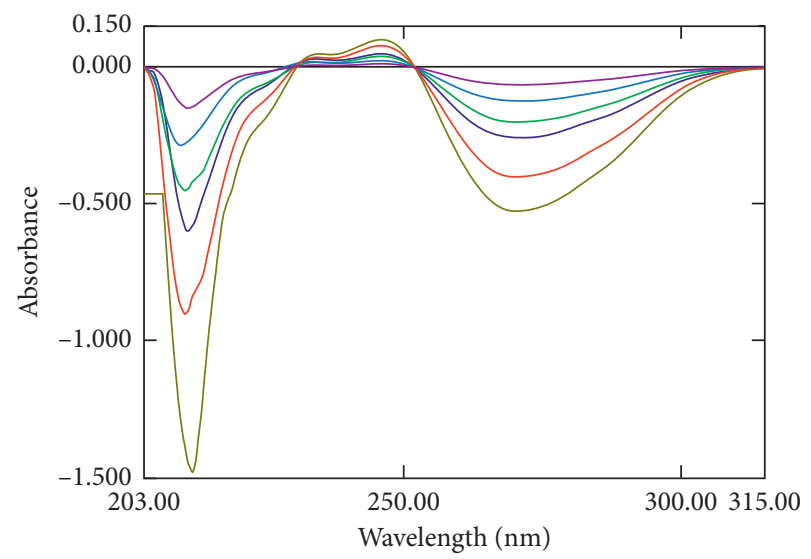

Figure 6: The first-order derivative spectra of COX 5 to $40 \mu \mathrm{g} / \mathrm{ml}$.

interfering another compound and excipients [38-40]. In this method, UV absorbance spectra of a mixture of AMD and COX were divided by the UV absorbance spectra of AMD solution to generate ratio spectra of COX in the concentration range of 5 to $40 \mu \mathrm{g} / \mathrm{ml}$ (Figure 8). Different concentration solutions of AMD were studied $(0.5,2,4,8$, and $10 \mu \mathrm{g} / \mathrm{ml}$ ) as a devisor; however, devisor concentration of $2 \mu \mathrm{g} / \mathrm{ml}$ was selected due to good sensitivity. Ratio spectra were converted into first derivative spectra using $4 \mathrm{~nm}$ as $\Delta \lambda$. First derivative spectra (Figure 9) showed two maxima at $222.92 \mathrm{~nm}$ and $258.24 \mathrm{~nm}$ and three minima at $-209.10 \mathrm{~nm}$, -232.35 , and $-286.7 \mathrm{~nm}$. The peak amplitude measured at these wavelengths was directly proportional to the concentration of COX. However, the amplitude at $222.92 \mathrm{~nm}$, $-209.10 \mathrm{~nm}$, and $232.35 \mathrm{~nm}$ was low, whereas at $286.7 \mathrm{~nm}$ showed good recovery of COX in the laboratory mixed samples with low RSD and good linearity with excellent regression coefficient $\left(r^{2}>0.999\right)$ when compared to amplitude measured at $258.24 \mathrm{~nm}$. Hence, $286.7 \mathrm{~nm}$ was

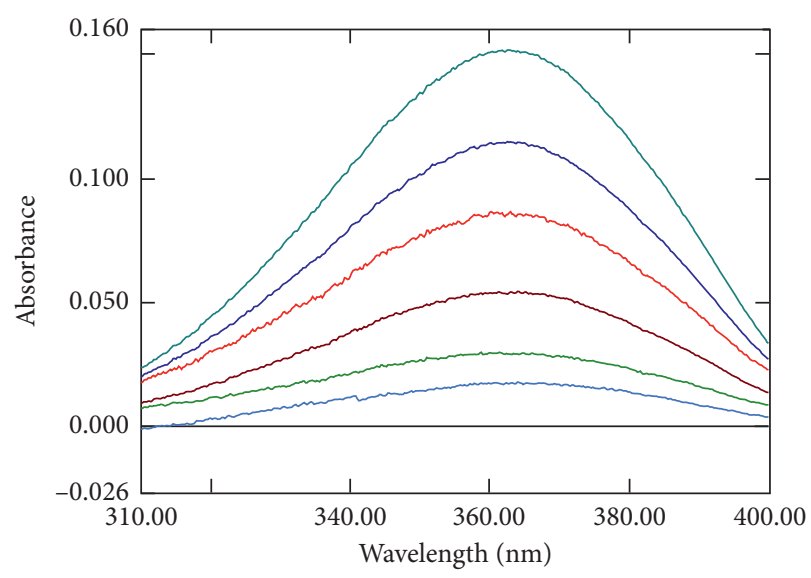

FIgURE 7: Normal spectra of AMD 1 to $10 \mu \mathrm{g} / \mathrm{ml}$ (second method).

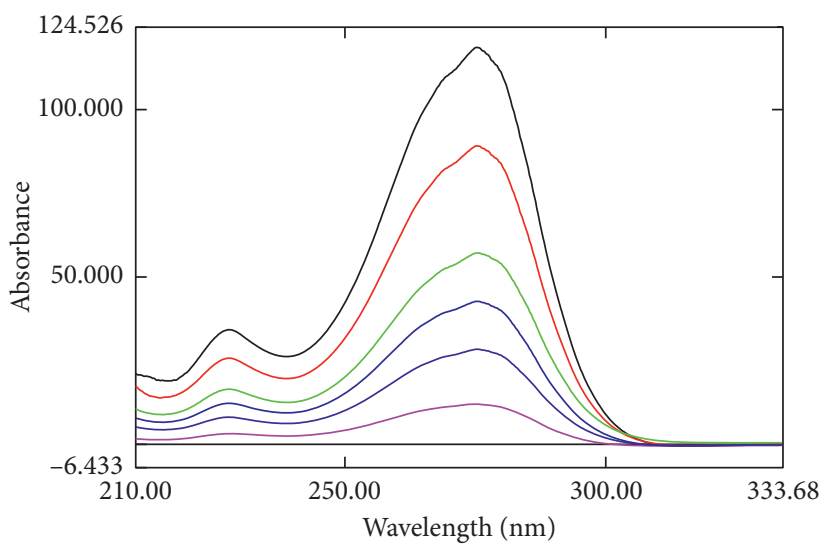

Figure 8: Ratio spectra of COX 5 to $40 \mu \mathrm{g} / \mathrm{ml}$ using AMD $2 \mu \mathrm{g} / \mathrm{ml}$ solution spectrum as a divisor.

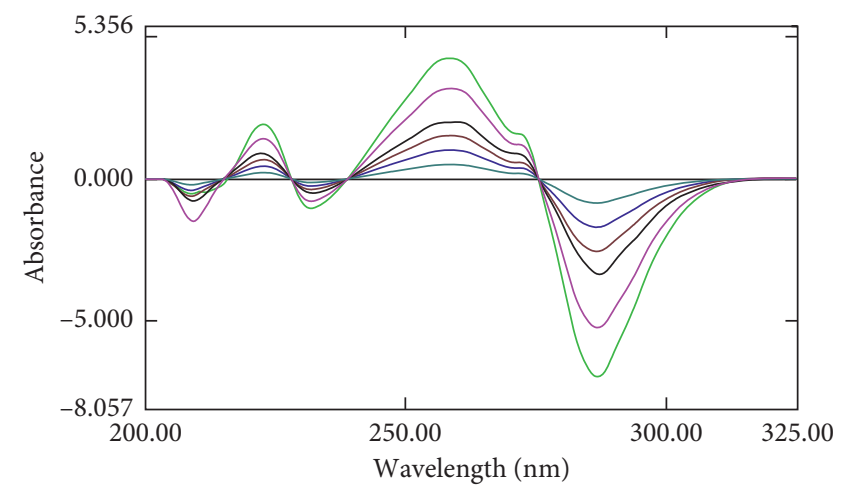

FIGURE 9: First-order ratio derivative spectra of COX 5 to $40 \mu \mathrm{g} / \mathrm{ml}$ using $4 \mathrm{~nm}$ as $\Delta \lambda$.

selected for analysis of COX. The peak amplitude was measured at $286.7 \mathrm{~nm}$ at different concentrations, and a calibration curve was constructed by plotting a graph between amplitude versus concentration of COX. Alternatively, the linearity equation was constructed from the calibration curve. 


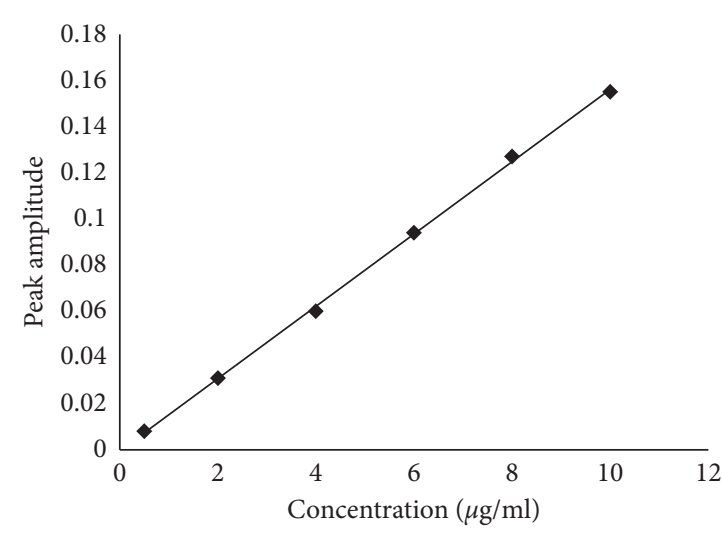

(a)

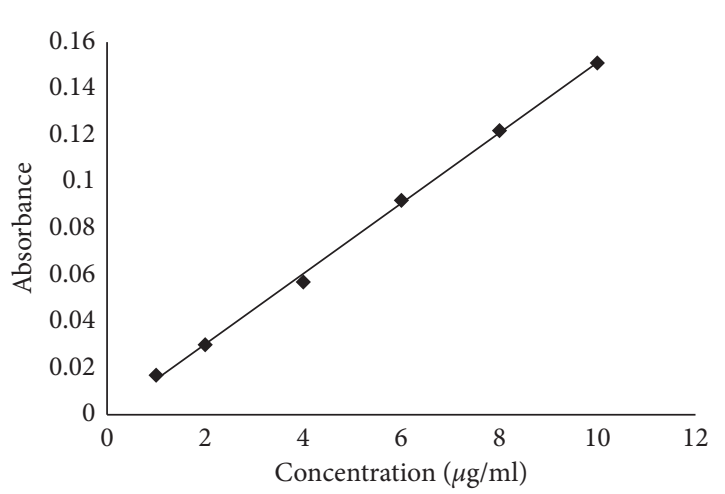

(c)

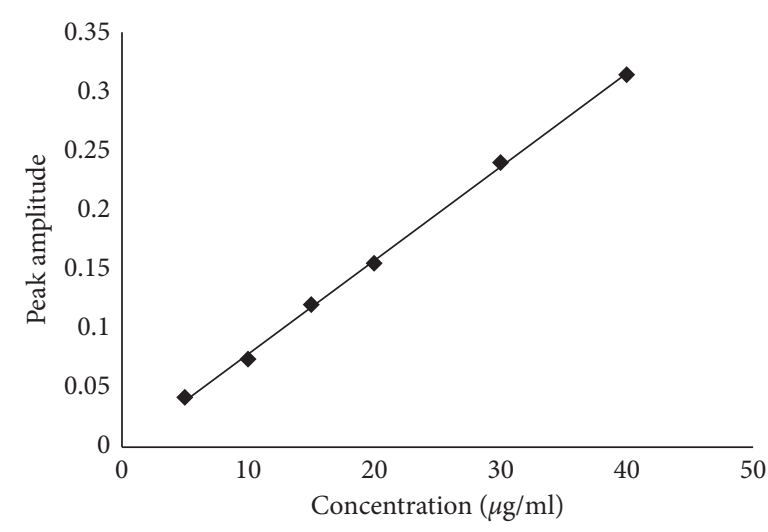

(b)

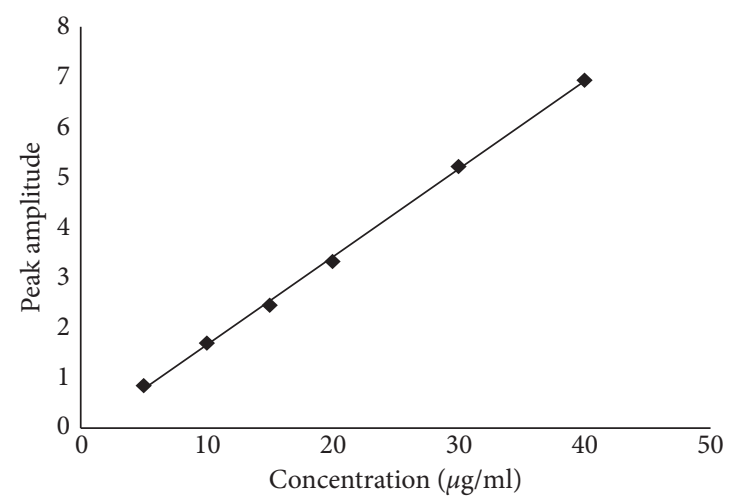

(d)

Figure 10: Calibration curves of AML 0.5 to $10 \mu \mathrm{g} / \mathrm{ml}$, first derivative method (a), 1 to $10 \mu \mathrm{g} / \mathrm{ml}$ in second method (normal absorption at $363.4 \mathrm{~nm}$ ) (c), COX 5 to $40 \mu \mathrm{g} / \mathrm{ml}$, first derivative method (b), and second method (first derivative of ratio spectra) (d).

4.1. Method Validation. Proposed spectroscopic procedures were validated adhering to the ICH guiding principles for linearity, the limit of detection and quantification, accuracy, precision, recovery, selectivity, and stability.

4.2. Linearity. The linearity range was determined for both analytes by both methods by analyzing the different concentration solutions. AMD exhibited excellent linearity in the concentration of 0.5 to $10 \mu \mathrm{g} / \mathrm{ml}$ in the first method and 1 to $10 \mu \mathrm{g} / \mathrm{ml}$ in the second method with good correlation coefficient $\left(r^{2}>0.998\right)$. COX was linear in the range of 5 to $40 \mu \mathrm{g} / \mathrm{ml}$ with an excellent correlation coefficient $\left(r^{2}>0.999\right)$ in both methods. The calibration curves for both analytes by both methods are shown in Figure 10. The linearity range, regression equations, and correlation coefficients are tabulated in Table 1.

4.3. Limits of Detection and Limits of Quantification. The sensitivity of the spectroscopic methods was established by determining the limits of detection (LOD) and limits of quantification (LOQ). LOD and LOQ were determined according to the ICH guidelines. LOD was determined by 3.3 $\mathrm{p} / \mathrm{m}$, whereas LOQ was determined by $10 \mathrm{p} / \mathrm{m}$, where $\mathrm{p}$ represents the standard deviation of calibration curve and $\mathrm{m}$ represents the slope of the curve. The low LOD and LOQ values showed the good sensitivity of the methods (Table 1).
TABLE 1: Regression equations and validation parameters results for AMD and COX.

\begin{tabular}{lcccc}
\hline \multirow{2}{*}{ Parameters } & \multicolumn{2}{c}{$\begin{array}{c}\text { First derivative } \\
\text { method }\end{array}$} & \multicolumn{2}{c}{ Second method } \\
Drugs & AMD & COX & AMD & COX \\
\hline Wave length $(\mathrm{nm})$ & -252.0 & -289.4 & 363.4 & -286.7 \\
Linearity range $(\mu \mathrm{g} / \mathrm{ml})$ & $0.5-10$ & $5-40$ & $1-10$ & $5-40$ \\
LOD $(\mu \mathrm{g} / \mathrm{ml})$ & 0.14 & 0.45 & 0.31 & 0.34 \\
LOQ $(\mu \mathrm{g} / \mathrm{ml})$ & 0.42 & 1.24 & 0.92 & 0.99 \\
Slop $(\mathrm{m})$ & 0.0157 & 0.0079 & 0.0151 & 0.1753 \\
Intercept $(\mathrm{c})$ & 0.0004 & -0.0004 & 0.0006 & -0.0947 \\
Correlation coefficient $\left(r^{2}\right)$ & 0.9992 & 0.9990 & 0.9985 & 0.9991 \\
\hline
\end{tabular}

4.4. Precision and Accuracy. The precision of the methods was assessed by interday and intraday precision (Supplementary material File (available here)). For intraday precision, the three different concentrations of both analytes were analyzed by an optimized method in triplicate on the same day. For interday precision, the same solutions were analyzed for three successive days. The precision was expressed as \% RSD, whereas accuracy was expressed as \% relative error and tabulated in Table 2. The low \% RSD $(<2.0)$ and low \% RE indicate good precision and accuracy of both methods.

4.5. Recovery Studies. Recovery studies of the spectroscopic methods were evaluated by the standard addition method 
TABle 2: Precision and accuracy data.

\begin{tabular}{|c|c|c|c|c|c|c|c|}
\hline & \multirow{2}{*}{$\begin{array}{l}\text { Amount of drug } \\
(\mu \mathrm{g} / \mathrm{mL})\end{array}$} & \multicolumn{3}{|c|}{ Interday } & \multicolumn{3}{|c|}{ Intraday } \\
\hline & & $\begin{array}{l}\text { Amount found mean } \\
\qquad(n=3) \pm \mathrm{SD}\end{array}$ & $\%$ RSD & \% RE & $\begin{array}{l}\text { Amount found mean } \\
\qquad(n=9) \pm \mathrm{SD}\end{array}$ & $\%$ RSD & $\% \mathrm{RE}$ \\
\hline \multicolumn{8}{|c|}{ First derivative method } \\
\hline \multirow{4}{*}{ AMD } & 1 & $1.01 \pm 0.01$ & 0.51 & 0.99 & $0.99 \pm 0.01$ & 1.02 & -1.01 \\
\hline & 4 & $3.93 \pm 0.05$ & 0.41 & -1.78 & $4.01 \pm 0.04$ & 1.00 & 0.25 \\
\hline & 8 & $7.94 \pm 0.18$ & 1.88 & -0.76 & $7.9 \pm 0.15$ & 1.90 & -1.27 \\
\hline & 5 & $4.96 \pm 0.05$ & 1.01 & -0.81 & $5.08 \pm 0.06$ & 1.18 & 1.57 \\
\hline \multirow{2}{*}{ COX } & 20 & $20.16 \pm 0.38$ & 1.51 & 0.79 & $19.76 \pm 0.31$ & 1.58 & -1.25 \\
\hline & 40 & $39.4 \pm 0.66$ & 1.7 & -1.52 & $40.08 \pm 0.59$ & 1.47 & 0.20 \\
\hline \multicolumn{8}{|c|}{ Second method } \\
\hline \multirow{3}{*}{ AMD } & 1 & $0.99 \pm 0.01$ & 1.02 & -1.01 & $0.98 \pm 0.01$ & 1.02 & -2.00 \\
\hline & 4 & $4.06 \pm 0.07$ & 1.14 & 1.48 & $3.94 \pm 0.06$ & 2.04 & -2.04 \\
\hline & 8 & $7.92 \pm 0.14$ & 1.97 & -1.01 & $7.86 \pm 0.17$ & 2.16 & -1.78 \\
\hline \multirow{3}{*}{$\mathrm{COX}$} & 5 & $4.91 \pm 0.03$ & 1.01 & -1.83 & $5.04 \pm 0.07$ & 1.39 & 0.79 \\
\hline & 20 & $19.67 \pm 0.21$ & 1.39 & -1.68 & $19.81 \pm 0.33$ & 1.67 & -0.96 \\
\hline & 40 & $39.85 \pm 0.71$ & 1.33 & -0.38 & $39.4 \pm 0.69$ & 1.75 & -1.52 \\
\hline
\end{tabular}

SD: standard deviation; \% RSD: percent relative standard deviation; \% RE: percent relative error.

TABLE 3: Recovery study results by the standard addition method.

\begin{tabular}{ccccc}
\hline & \multicolumn{2}{c}{ First derivative method } & \multicolumn{2}{c}{ Second method } \\
& Amount added $(\mu \mathrm{g} / \mathrm{ml})$ & \% Recovery & Amount added $(\mu \mathrm{g} / \mathrm{ml})$ & 98.49 \\
& 1 & 98.87 & 1 & 101.12 \\
99.44 & 99.68 \\
AMD & 2 & 100.94 & 3 & 1.33 \\
& 3 & 99.09 & & 99.17 \\
Across mean & 99.63 & 5 & 101.39 \\
\% RSD & 5 & 1.14 & 10 & 99.28 \\
& 10 & 101.23 & 15 & 99.95 \\
& 15 & 98.77 & & 1.25 \\
\hline
\end{tabular}

(Supplementary material File (available here)). Three different concentration solutions of $\operatorname{AMD}(1,2$, and $3 \mu \mathrm{g} / \mathrm{ml})$ and $\operatorname{COX}(5,10$, and $15 \mu \mathrm{g} / \mathrm{ml})$ were added separately to the previously analyzed formulation solution consisting of $1 \mu \mathrm{g} /$ $\mathrm{ml}$ of AMD and $20 \mu \mathrm{g} / \mathrm{ml}$ of COX. Then, the total amount of AMD and COX were determined using the corresponding regression equations, and the amount of added analyte concentrations was computed. The accuracy was expressed as percentage recovery and $\% \mathrm{RSD}$ (Table 3 ). The percentage recovery was in the range of $98.70 \%$ to $101.83 \%$ with low $\%$ RSD (<2\%), which indicates the best accuracy of the methods.

4.6. Stability Studies. Standard stock solutions and working standard solutions were stored in the refrigerator at $4^{\circ} \mathrm{C}$ and analyzed on a daily basis for 7 days. No variation in the concentration of both analytes was observed even on the 7 th day, which indicates the stability of both analytes.

4.7. Application of Proposed Methods for Determination AMD and COX from the Formulation Mixture and Laboratory-
Prepared Tablets. Both UV spectroscopic procedures were effectively utilized for quantification of AMD and COX from the formulation mixture and laboratory prepared tablets (Supplementary material File (available here)). Fixed-dose combination of AMD and COX was not available in the local market; hence, separate formulations of AMD and COX were mixed in the proposition to get the concentration of coformulation, and tablets were prepared in laboratory and analyzed. The analysis results (Table 4) were in agreement with the amount of AMD and COX in the formulation. Further recovery studies results (Table 3) were also in agreement with the amount of AMD and COX added to the previously analyzed mixture. The validity of the methods was assessed by determining the accuracy of the methods by the standard addition method. The analysis results (Tables 3 and 4) with low \% RSD showed the excellent accuracy and precision of the methods. In addition, it also proved the absence of excipients' interference in the analysis of analytes from formulations. Furthermore, the determined " $t$ " and " $F$ " values were less than the critical " $t$ " and " $F$ " values (Table 5), indicating that there is no significant difference in the analysis results between the two methods. 
TABLE 4: Determination of AMD and COX from formulation mixture and tablets.

\begin{tabular}{|c|c|c|c|c|c|}
\hline & \multirow{2}{*}{ Formulation ratio (mg/Tab) } & \multicolumn{2}{|c|}{$\begin{array}{c}\text { First derivative method } \\
\text { \% Recovery }\end{array}$} & \multicolumn{2}{|c|}{$\begin{array}{l}\text { Second method } \\
\% \text { Recovery }\end{array}$} \\
\hline & & Formulation mixture & Tablets & Formulation mixture & Tablets \\
\hline AMD & 10 & 98.41 & 98.54 & 99.08 & 98.55 \\
\hline $\mathrm{COX}$ & 200 & 99.29 & 101.87 & 98.90 & 99.03 \\
\hline AMD & 5 & 99.21 & 101.08 & 100.36 & 100.89 \\
\hline COX & 200 & 98.58 & 98.14 & 98.49 & 101.38 \\
\hline AMD & 2.5 & 98.70 & 100.98 & & \\
\hline $\mathrm{COX}$ & 200 & 101.37 & 98.06 & & \\
\hline
\end{tabular}

TABle 5: Statistical results of the comparison between the two proposed methods.

\begin{tabular}{lcc}
\hline Parameters & AMD $(n=6)$ & COX $(n=6)$ \\
\hline Average (\% recovery) & 99.58 & 100.09 \\
$\%$ RSD & 0.69 & 1.36 \\
$T(2.570)^{\mathrm{a}}$ & 1.385 & 0.621 \\
$F(5.050)^{\mathrm{b}}$ & 2.171 & 1.034 \\
\hline
\end{tabular}

aThe critical " $t$ " value. ${ }^{\mathrm{b}}$ Critical " $F$ " value at $(P=0.05)$.

\section{Conclusions}

Two simple UV spectroscopic procedures have been established for determination of AMD and COX in the presence of each other and excipients. These are the first analytical methods reported for determination of AMD and COX in the presence of each other. Both methods are simple, economical, eco-friendly, accurate, and precise. The first derivative spectroscopic method can determine both the analytes in a binary mixture in two steps: derivatization and measurement of amplitude at zero-crossing wavelength. On the other hand, the second method involves direct measurement of AMD and COX, which has been analyzed in three steps: division for ratio, derivatization, and measurement of amplitude; however, ratio derivatization gives many maxima and minima to determine the amount of analyte in the presence of another analyte. Finally, both the methods have been successfully applied for the determination of AMD and COX from formulation mixture and laboratory-prepared tablets. The statistical comparison results confirm that there is no significant difference between the two proposed methods.

\section{Data Availability}

The UV spectral data used to support the findings of this study are included within the article and supplementary information files.

\section{Conflicts of Interest}

The authors have no conflicts of interest.

\section{Acknowledgments}

The authors acknowledge the Deanship of Scientific Research at King Faisal University for the financial support under Nasher Track (Grant No. 186160).

\section{Supplementary Materials}

File 1: first derivative spectra of $\mathrm{AMD}$ and $\mathrm{COX}$ for precision and accuracy. File 2: (A) normal spectra of AMD and COX in a ratio $2: 5,4: 20$, and $8: 40 \mu \mathrm{g} / \mathrm{ml}$. Enlarged part for AMD $(2,4,8 \mu \mathrm{g} / \mathrm{ml})$ for measuring absorption at 363.4 ; (B) first derivative of ratio spectra of $\mathrm{C} 5,20$, and $40 \mu \mathrm{g} / \mathrm{ml}$ for precision and accuracy. File 3: first derivative of Mixture of $\mathrm{AMD}$ and COX in a ratio $1: 20$ (formulation), $2: 25,3: 30$, and $4: 35 \mu \mathrm{g} / \mathrm{ml}$, respectively, for formulation and recovery studies. File 4: (A) ratio spectra of COX 20, 25, 30, and $35 \mu \mathrm{g} /$ $\mathrm{ml}$ using AMD $(2 \mu \mathrm{g} / \mathrm{ml})$ solution spectrum as devisor; (B) first derivative of ratio spectra of COX 20, 25, 30, and $35 \mu \mathrm{g} /$ $\mathrm{ml}$ using $4 \mathrm{~nm}$ as $\Delta \lambda$ for formulation and recovery studies. File 5: (A) normal spectra of AMD and COX in a ratio (a) $0.5: 20$, (b) $1: 20$, and (c) $0.5: 40 \mu \mathrm{g} / \mathrm{ml}$; (B) first derivative spectra of AMD and COX in a ratio (a) $0.5: 20$, (b) $1: 20$, and (c) $0.5: 40 \mu \mathrm{g} / \mathrm{ml}$; (C) (first method) ratio spectra of tablet solution of (a) COX $20 \mu \mathrm{g} / \mathrm{ml}$ and (b) COX $40 \mu \mathrm{g} / \mathrm{ml}$ using AMD $(2 \mu \mathrm{g} / \mathrm{ml})$ solution spectrum as devisor; (D) first derivative of ratio spectra of tablet solution of (a) COX $20 \mu \mathrm{g} /$ $\mathrm{ml}$ and (b) COX $40 \mu \mathrm{g} / \mathrm{ml}$ using $4 \mathrm{~nm}$ as $\Delta \lambda$. (Supplementary Materials)

\section{References}

[1] P. Verdecchia, F. Angeli, G. Mazzotta et al., "Treatment strategies for osteoarthritis patients with pain and hypertension," Therapeutic Advances in Musculoskeletal Disease, vol. 2, no. 4, pp. 229-240, 2010.

[2] A. Hirayama, N. Tanahashi, H. Daida et al., "Assessing the cardiovascular risk between celecoxib and nonselective nonsteroidal antiinflammatory drugs in patients with rheumatoid arthritis and osteoarthritis," Circulation Journal, vol. 78, no. 1, pp. 194-205, 2014.

[3] F. K. Chan, A. Lanas, J. Scheiman, M. F. Berger, H. Nguyen, and J. L. Goldstein, "Celecoxib versus omeprazole and diclofenac in patients with osteoarthritis and rheumatoid arthritis (CONDOR): a randomised trial," The Lancet, vol. 376, no. 9736, pp. 173-179, 2010.

[4] C. Walker, "Are all oral COX-2 selective inhibitors the same? A consideration of celecoxib, etoricoxib, and diclofenac," International Journal of Rheumatology, vol. 2018, Article ID 1302835, 12 pages, 2018.

[5] S. M. Smith and R. M. Cooper-DeHoff, "Fixed-dose combination amlodipine/celecoxib (consensi) for hypertension and osteoarthritis," The American Journal of Medicine, vol. 132, no. 2, pp. 172-174, 2019. 
[6] S. C. Sweetman, Martindale, The Complete Drug Reference, The Pharmaceutical Press, London, UK, 37th edition, 2011.

[7] N. T. Q. Trang, N. V. Hop, N. D. G. Chau, and T. B. Tran, "Simultaneous determination of amlodipine, hydrochlorothiazide, and valsartan in pharmaceutical products by a combination of full spectrum measurement and kalman filter algorithm," Advances in Materials Science and Engineering, vol. 2019, Article ID 5719651, 9 pages, 2019.

[8] N. Usharani, K. Divya, and V. V. S. Ashrtiha, "Development and validation of UV-derivative spectroscopic and RP-HPLC methods for the determination of amlodipine besylate and valsartan in tablet dosage form and comparison of the developed methods by student's T-test," Indian Journal of Pharmaceutical Education and Research, vol. 51, no. 4s, pp. s776-s782, 2017.

[9] M. Desavathu, P. Raghuveer, and P. Sarada, "Insertion of dual drugs of hypertension in gelatin pockets for chrono pharmacotherapy and its evaluation by in-vitro and ex- vivo studies," Indian Journal of Pharmaceutical Education and Research, vol. 52, no. 4s, pp. s184-s196, 2018.

[10] H. M. Abdel-Wadood, N. A. Mohamed, and A. M. Mahmoud, "Validated spectrofluorometric methods for determination of amlodipine besylate in tablets," Spectrochimica Acta Part A: Molecular and Biomolecular Spectroscopy, vol. 70, no. 3, pp. 564-570, 2008.

[11] J. J. Pandya, M. Sanyal, and P. S. Shrivastav, "Simultaneous densitometric analysis of amlodipine, hydrochlorothiazide, lisinopril, and valsartan by HPTLC in pharmaceutical formulations and human plasma," Journal of Liquid Chromatography \& Related Technologies, vol. 40, no. 9, pp. 467-478, 2017.

[12] A. M. Brondi, J. S. Garcia, and M. G. Trevisan, "Development and validation of a chromatography method using tandem $\mathrm{UV} /$ charged aerosol detector for simultaneous determination of amlodipine besylate and olmesartan medoxomil: application to drug-excipient compatibility study," Journal of Analytical Methods in Chemistry, vol. 2017, Article ID 4878316, 8 pages, 2017.

[13] I. Kasagić-Vujanović, B. Jančić-Stojanović, and D. Ivanović, "Investigation of the retention mechanisms of amlodipine besylate, bisoprolol fumarate, and their impurities on three different ILIC columns," Journal of Liquid Chromatography \& Related Technologies, vol. 41, no. 9, pp. 523-531, 2018.

[14] D. Sangeetha and M. K. Vadlamudi, "Stability-indicating method for the determination of assay and quantification of impurities in amlodipine-atorvastatin combination dosage form by RP-HPLC," Journal of Liquid Chromatography \& Related Technologies, vol. 40, no. 11, pp. 576-598, 2017.

[15] L. Wang, W. Liu, Z. Zhang, and Y. Tian, "Validated LC-MS/ MS method for the determination of amlodipine enantiomers in rat plasma and its application to a stereoselective pharmacokinetic study," Journal of Pharmaceutical and Biomedical Analysis, vol. 158, pp. 74-81, 2018.

[16] P. E. Irden, I. H. Taşdemir, C. Kaçar, and E. Kiliç, "Simultaneous determination of valsartan and Amlodipine besylate in human serum and pharmaceutical dosage forms by voltammetry," International Journal of Electrochemical Science, vol. 9, pp. 2208-2220, 2014.

[17] E. Arkan, Z. Karimi, M. Shamsipur, and R. Saber, "An electrochemical senor for determination of amlodipine besylate based on graphene-chitosan nano composite film modified glassy carbon electrode and application in biological and pharmaceutical samples," Journal of Pharmaceutical Sciences, vol. 3, pp. 99-107, 2014.
[18] G. R. Mansano, A. P. P. Eisele, L. H. Dall'Antonia, S. Afonso, and E. R. Sartori, "Electroanalytical application of a borondoped diamond electrode: improving the simultaneous voltammetric determination of Amlodipine and valsartan in urine and combined dosage forms," Journal of Electroanalytical Chemistry, vol. 738, pp. 188-194, 2015.

[19] A. S. Rajpurohit, D. K. Bora, and A. K. Srivastava, “"Simultaneous determination of Amlodipine and losartan using an iron metal-organic framework/mesoporous carbon nanocomposite-modified glassy carbon electrode by differential pulse voltammetry," Analytical Methods, vol. 10, no. 45, pp. 5423-5438, 2018.

[20] E. Djaalab, M. Samar, S. Zougar, and R. Kherrat, "Electrochemical biosensor for the determination of amlodipine besylate based on gelatin-polyaniline iron oxide biocomposite film," Catalysts, vol. 8, no. 6, p. 233, 2018.

[21] E. Mircia, T. Balaci, G. Hancu, V. Ion, and A. Cârje, "Simultaneous determination of amlodipine and atorvastatin by capillary electrophoresis from fixed pharmaceutical formulations," FARMACIA, vol. 64, no. 3, pp. 398-402, 2016.

[22] M. Attimarad, N. Sreeharsha, B. E. Al-Dhubaib, A. B. Nair, and K. N. Venugopala, "Capillary electrophoresis: MEKC assay method for simultaneous determination of olmesartan medoxomil, Amlodipine besylate and hydrochlorothiazide in tablets," Indian Journal of Pharmaceutical Education and Research, vol. 50, no. 2, pp. 188-195, 2016.

[23] M. Adriana, H. Gabriel, R. Alexandru Vlad, S. Ştefana, R. Soare, and H. Kelemen, "Simultaneous determination of Amlodipine and telmisartan from pharmaceutical products by way of capillary electrophoresis," Current Issues in Pharmacy and Medical Sciences, vol. 29, no. 1, pp. 42-46, 2016.

[24] S. E. Nissen, N. D. Yeomans, D. H. Solomon et al., "Cardiovascular safety of celecoxib, naproxen, or ibuprofen for arthritis," New England Journal of Medicine, vol. 375, no. 26, pp. 2519-2529, 2016.

[25] F. Angeli, M. Trapasso, S. Signorotti, P. Verdecchia, and G. Reboldi, "Amlodipine and celecoxib for treatment of hypertension and osteoarthritis pain," Expert Review of Clinical Pharmacology, vol. 11, no. 11, pp. 1073-1084, 2018.

[26] R. E. Harris, G. A. Alshafie, H. Abou-Issa et al., "Chemoprevention of breast cancer in rats by celecoxib, a cyclooxygenase 2 inhibitor," Cancer Research, vol. 60, no. 8, pp. 2101-2103, 2000.

[27] R. N. Saha, C. Sajeev, P. R. Jadhav, S. P. Patil, and N. Srinivasan, "Determination of celecoxib in pharmaceutical formulations using UV spectrophotometry and liquid chromatography," Journal of Pharmaceutical and Biomedical Analysis, vol. 28, no. 3-4, pp. 741-751, 2002.

[28] A. A. Gouda, M. I. Kotb El-Sayed, A. S. Amin, and R. El Sheikh, "Spectrophotometric and spectrofluorometric methods for the determination of non-steroidal anti-inflammatory drugs: a review," Arabian Journal of Chemistry, vol. 6, no. 2, pp. 145-163, 2013.

[29] R. N. Saha, S. Chandran, P. R. Jadhav, and P. B. Kharwade, "Rapid and sensitive spectrofluorimetric method for the estimation of celecoxib and flurbiprofen," Indian Journal of Pharmaceutical Sciences, vol. 68, no. 1, pp. 20-25, 2006.

[30] J. Emami, R. Fallah, and A. Ajami, "A rapid and sensitive HPLC method for the analysis of celecoxib in human plasma: application to the pharmacokinetic studies," DARU Journal of Pharmaceutical Sciences, vol. 16, pp. 211-217, 2008.

[31] H. R. Bapatu, R. Maram, and S. Murthy, "Stability-indicating HPLC method for quantification of celecoxib and diacerein 
along with its impurities in capsule dosage form," Journal of Chromatographic Science, vol. 53, no. 1, pp. 144-153, 2015.

[32] O. S. S. Chandana and R. Ravichandrababu, "Stability indicating HPLC method for celecoxib related substances in solid dosage forms," International Journal of Research in Pharmaceutical Sciences, vol. 7, no. 1, pp. 10-18, 2017.

[33] M.-S. Park, W.-S. Shim, S.-V. Yim, and K.-T. Lee, "Development of simple and rapid LC-MS/MS method for determination of celecoxib in human plasma and its application to bioequivalence study," Journal of Chromatography B, vol. 902, pp. 137-141, 2012.

[34] N. P. Patel, M. Sanyal, P. S. Shrivastav, and B. N. Patel, "Estimation of celecoxib in human plasma by rapid and selective LC-MS/MS method for a bioequivalence study," International Journal of Pharmacy and Pharmaceutical Sciences, vol. 10, no. 10, pp. 16-22, 2018.

[35] M. K. Srinivasu, D. Sreenivas Rao, and G. O. Reddy, "Determination of celecoxib, a COX-2 inhibitor, in pharmaceutical dosage forms by MEKC," Journal of Pharmaceutical and Biomedical Analysis, vol. 28, no. 3-4, pp. 493-500, 2002.

[36] A. H. Kamal, S. F. El-Malla, and S. F. Hammad, "A Review on UV spectrophotometric methods for simultaneous multicomponent analysis," European Journal of Pharmaceutical and Medical Research, vol. 3, pp. 348-360, 2016.

[37] M. Attimarad, M. Shahzad Chohan, and A. Ahmed Balgoname, "Simultaneous determination of moxifloxacin and flavoxate by RP-HPLC and ecofriendly derivative spectrophotometry methods in formulations," International Journal of Environmental Research and Public Health, vol. 16, no. 7, p. 1196, 2019.

[38] F. Salinas, J. J. B. Nevado, and A. E. Mansilla, "A new spectrophotometric method for quantitative multicomponent analysis resolution of mixtures of salicylic and salicyluric acids," Talanta, vol. 37, no. 3, pp. 347-351, 1990.

[39] A. Afkhami and M. Bahram, "Successive ratio-derivative spectra as a new spectrophotometric method for the analysis of ternary mixtures," Spectrochimica Acta Part A: Molecular and Biomolecular Spectroscopy, vol. 61, no. 5, pp. 869-877, 2005.

[40] N. M. Bhatt, V. D. Chavada, M. Sanyal, and P. S. Shrivastav, "Manipulating ratio spectra for the spectrophotometric analysis of diclofenac sodium and pantoprazole sodium in laboratory mixtures and tablet formulation," The Scientific World Journal, vol. 2014, Article ID 495739, 10 pages, 2014. 

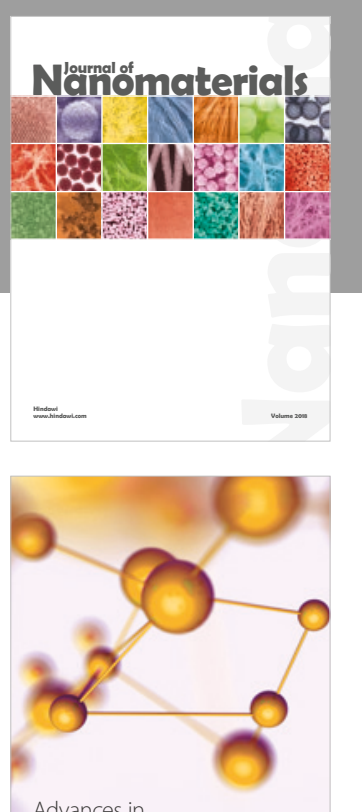

Physical Chemistry
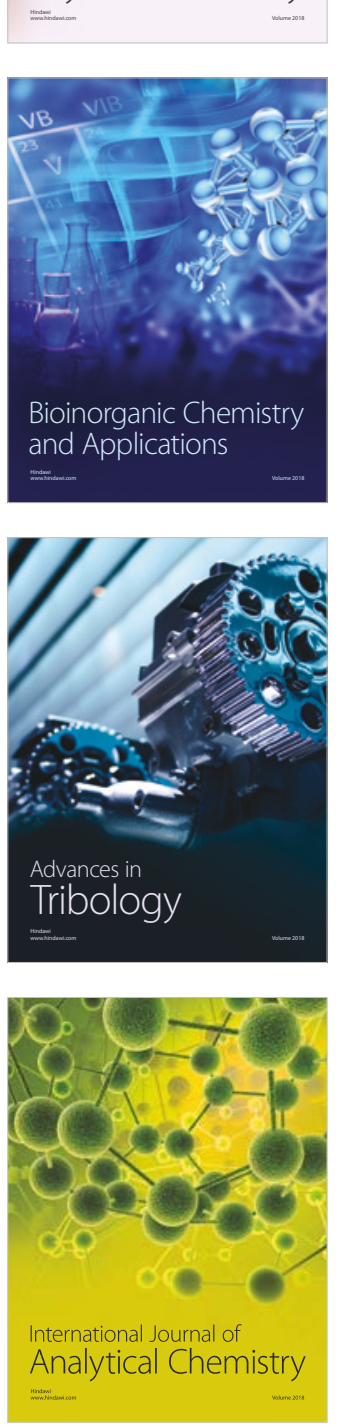

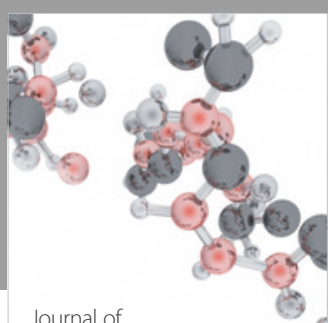

Analytical Methods

in Chemistry

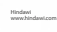

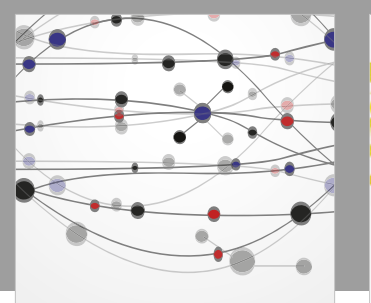

The Scientific World Journal

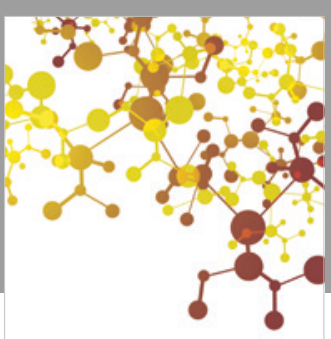

Journal of

Applied Chemistry
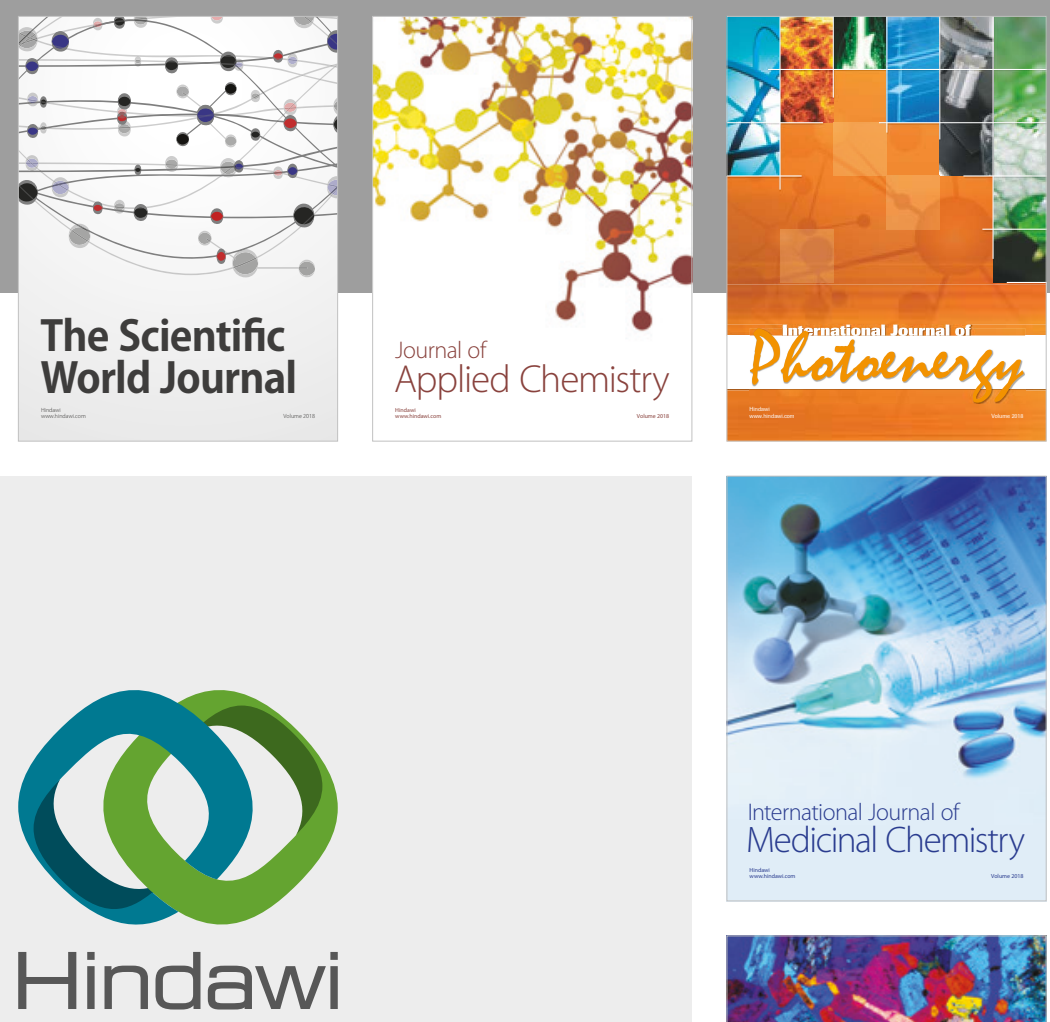

Submit your manuscripts at

www.hindawi.com
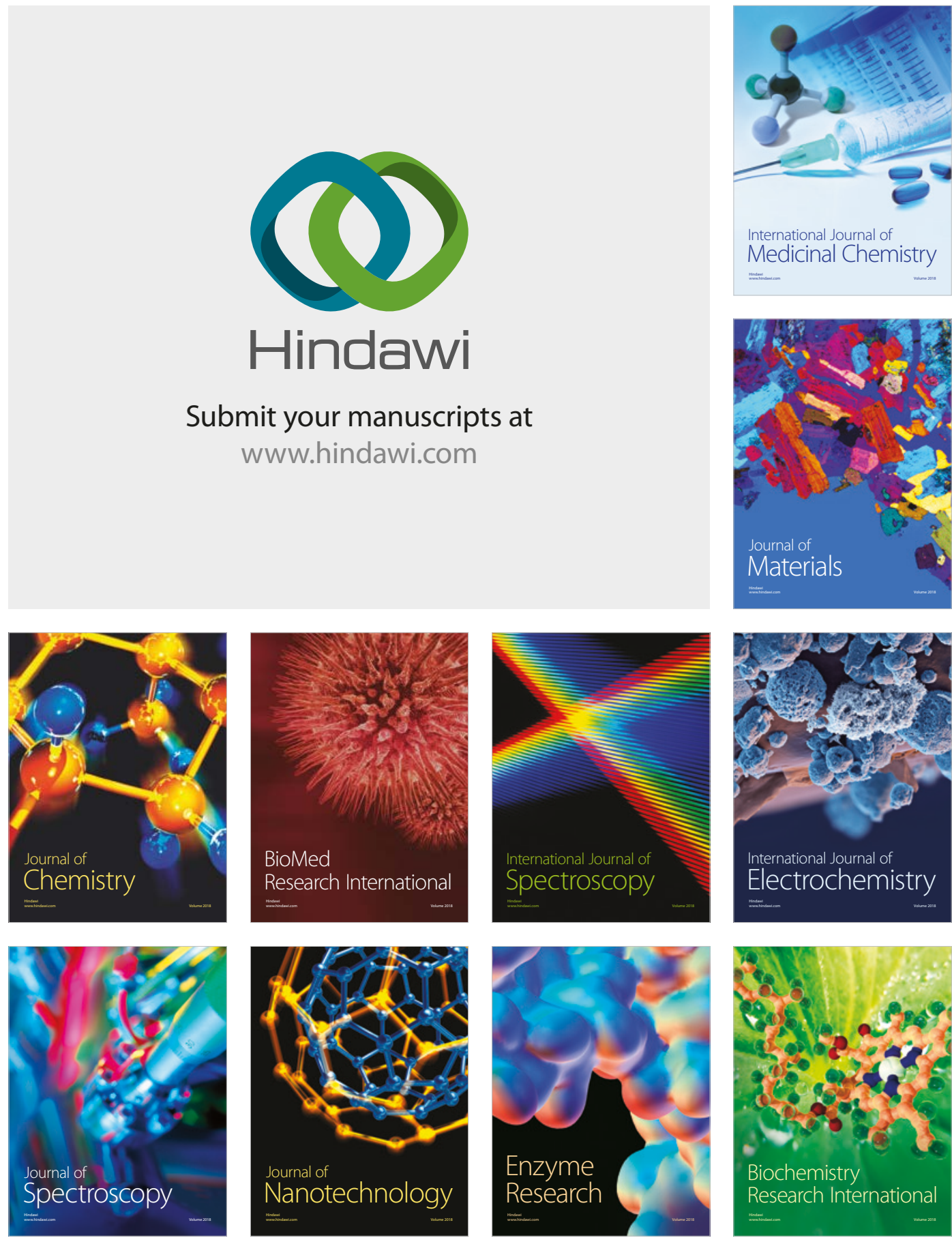
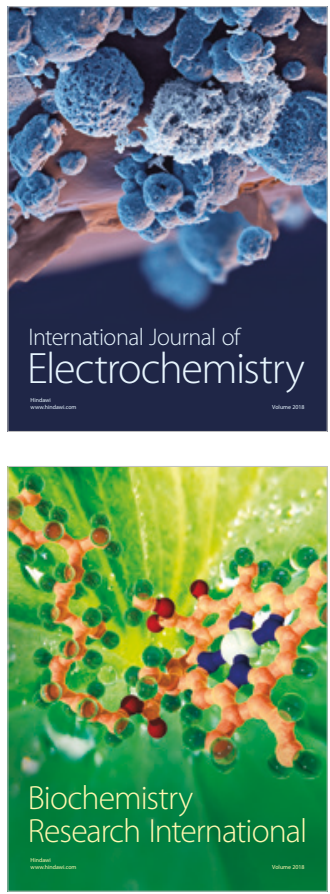